\title{
Research on Problem about Technology Insurance Pricing based on Backward Stochastic Differential Equation Theory
}

\author{
Siyun $\mathrm{Xu}$, Zhuhua Han \\ Hebei Finance University, Science and Technology Financial Key Laboratory of Hebei Province, Baoding, 071051, China
}

\begin{abstract}
The development of Backward Stochastic Differential Equation Theory is just a thing happened in the past years. Although its development and application is far behind Forward Stochastic Differential Equation, its wide application prospect on financial mathematics gets more and more attention. The meaning of Backward Stochastic Differential Equation is that change a already-known final (usually uncertain) goal into a present certain answer to make a present resolution. But Insurance Pricing happens to know the final result, it's certain that the result is uncertain, that is to say, to get out of danger or not. And then make present insurance price according to the future uncertain result. The Insurance Pricing just follows the meaning of Backward Stochastic Differential Equation. Insurance Pricing itself is also a research field sprang up in past scores of years, because insurance pricing is the indisputable core of insurance work, and gets quite a few researchers' attention. This article adopts backward stochastic differential equation theory and do research on problem about technology insurance pricing.
\end{abstract}

Keywords-backward stochastic differential equation theory; technology insurance; pricing research.

\section{RELEVANT SUMMARY ABOUT BACKWARD STOCHASTIC DIFFERENTIAL EQUATION}

In order to introduce the backward stochastic differential equation, we need make a contrast to the classical (forward) stochastic differential equation. The research on forward stochastic differential equation has a history of nearly half a century and gains glorious achievements. It not only has direct application background, but also has a very natural and often unexpected link with other branches of math such as measure theory v partial differential equation、 differential geometry and potential theory and so on. They promote and complete one another. Many mathematicians were absorbed in them and made outstanding contribution in this field, which promote other subjects' development in return. A recent typical example is that the viscosity solution theory of nonlinear second-order partial differential equation put forward by RLLions, whose direct motivation is from his research on stochastic differential equation and stochastic control theory. What makes sharp contrast is that: the research on backward stochastic differential equation just begins, whose linear case is raised by Bislnut in 1978, and the basic framework of nonlinear case is raised and proved its unique existence by Shige Peng and Pardoux in 1990. Very coincidently, in research on economics, famous economist Duffie and
Epstein also put the typical case of this equation independently in 1992. The research on backward stochastic differential equation a lot far behind forward stochastic differential equation may has following two reasons by stepping back and analyzing: first, the structure of backward stochastic differential equation and forward stochastic differential equation is different in nature. So it's difficult to guess the form of the backward stochastic differential equation from the forward stochastic differential equation. Next, from the perspective of application, forward stochastic differential equation is about how to know the random process of a objective existence, while backward stochastic differential equation mainly cares about how to make a system to reach an expected goal in a randomly-disturbed environment. From the perspective of epistemology, it's natural for backward stochastic differential equation to fall behind.

\section{THE THEORETICAL FOUNDATION OF APPLYING BACKWARD STOCHASTIC DIFFERENTIAL EQUATION TO PRICE INSURANCE}

\section{A. The need of insurance industry of science and technology itself}

Chinese insurance industry has developed rapidly since the domestic insurance service was restored. However, work becomes more and more difficulty with the development of the business. Among them, the over-high insurance rate is an important factor which affects the further development of insurance industry, because domestic insurance industry is gradually developed with commodity economy. Enterprises and individuals need consider not only the security and supportability of their management or life, but also consider their economic reckoning and economic interest. So the excessive rate will affect their positivity to invest in insurance. And insurance investment is a voluntarily conduct. It's unfavorable to implement activity on renewal of insurance if excessive rate is kept. The most fundamental reasons which affect the development of insurance industry are these: the one is the income level of residents: the other is the price of insurance. As insurance company, it cannot control the former, but it can control the latter. By applying the insurance capital, insurance company can increase profits and supply the material guarantee for decreasing premium reasonably. In this way, insurance company can solve properly the paradox between insurance and profit, and make the 
insurance company's desire to make profit in accordance with the requirement of society's need to decrease premium. Applying insurance capital independently can attach the running achievement of insurance industry to material profit, and promote the interior motivation to increase profit and amplify the amount of insurance desire. By applying the time difference of debt-based capital, insurance company can further increase profit, and then increase the insurance fund reserve to support larger business. Such a virtuous circle makes insurance business prosper.

\section{B. Utility function exists much randomness}

At present, international insurance industry's application of insurance fund reserve becomes a economic conduct and a universal phenomenon of insurance industry. The development of insurance industry all over the world has a common tendency, that is, the scope of insurance becomes wider and wider, the competition among companies becomes fiercer and fiercer. In order to gain customers and strive for existence in competition, every insurance company has to accept insurance with various favorable terms, one of them is decrease premium, even sometimes lower than compensation, which cause some insurance companies cannot make the ends meet with premium they charged and report a loss. As a result, they have to depend on the profit they made by directly applying insurance fund reserve to make up for the loss caused by low premium, on which insurance companies to exist and develop. So, collecting the premium here is a method of financing of insurance companies. From above we can see that the insurance industries' application of insurance fund reserve to make profit not only becomes an important content of insurance industry in some countries nowadays, but also one of important premises of their existence and development. The investment problem of insurance capital has become an important research content of actuarial studies. These years, the research on applying insurance capital has developed in the foreign countries, but they still divide the research of applying insurance capital into insurance and investment, that is to say, divide the insurance into two parts, one is accepting insurance, the other is investing. Accepting insurance only consider the risk of accepting insurance while investing only consider the risk of investing. However, in fact, these two are inseparable :on the one hand, the premium in the business of accepting insurance determines directly the amount of invest-able money ; on the other hand, the benefit of applying capital will have an influence on the pricing of premium and the ability to compensate. If insurance companies ignore the mutual effect between the price of product and the risk of investment, that will make the price of premium cannot reflect well on problems such as their own actual power and the investment to insurance hard to go on. Through investing to insurance, we can know the price of insurance, whose reasonability can show the position of insurer in the market and get the most effective capital application. Of course, in addition to that, some articles has considered the risk of accepting insurance, but they all used utility function inevitably, which has much dispute and often too random to control.

\section{The Advantages of Backward Stochastic Differential Equation}

Backward Stochastic Differential Equation has plentiful mathematical properties and now people discover that Backward Stochastic Differential Equation is same as many research methods of economics and finance and its application prospect is very wide. Then the author is going to employ the accepting insurance and the time-lag of insurance paying to invest on accepted insurance, take the risk of accepting insurance as control variable, take backward stochastic differential equation and relevant as tools, study the insurance pricing from the perspective of investing and establish the model of insurance pricing, discover and affect the price of insurance by investment and offer evidence to the adjustment of the price of insurance in insurance companies, and achieve the goal to increase the actual power of insurance enterprises.

\section{Determine the price of science and technology's insurance by using backward stochastic differential equation}

(1) The establishment of mathematical model

Establish the model of determine the price of science and technology's insurance in the frame of venture investment. The basic method and steps are as follows:

First, suppose that there's only two types of property, risk-free property and risky property. Ignore the transaction cost, revenue and bonus. That is:

$$
\left\{\begin{array}{c}
d x_{0}(t)=r_{0} x_{0}(t) d t \\
d x_{1}(t)=r_{1} x_{1}(t) d t+\sigma x_{1}(t) d w(t)
\end{array}\right.
$$

In the formul, $x_{0}(t) x_{1}(t)$ respectively represent the prices of risk-free property and risky property, $r_{0} r_{1}$ respectively represent the yield of risk-free property and risky property, $\sigma$ represents volatility of risky property.

Then suppose some insurance's price is $\mathrm{P}$, the amount of insurance is $\mathrm{Q}, \quad \xi$ is compensation claims frequency, the random variable. And suppose the rate of operating expense of companies to premium is $\mathrm{h}$, then the insurance expenses is $\mathrm{PQ}$, the compensation at the moment of $\mathrm{t}=\mathrm{T}$ is $\xi \mathrm{Q}$,

The expenses that can be invested is (1-h) PQ.

Thirdly, to combine the risky investment. Suppose $\pi(t)$ as the ratio of investment to risky property , $\pi$

$(t) \in[0,1]$. The gross property at the moment of $t$ is $y(t)$.So $y(t) \pi(t)$ is the investment to risky property, $y(r)[1-\pi(t)]$ is the investment to risk-free property. Plug the Ito differential equation into (1), and we can get the gross property $\mathrm{y}(\mathrm{t})$ meet the differential equation: 


$$
\left\{\begin{array}{c}
d x(t)=\left[r_{0}+r \pi(t)\right] y(t) d t+\sigma \pi(t) d w(t) \\
y(0)=(1-h) P Q \\
r=r_{1}-r_{2}
\end{array}\right.
$$

Then we can get the following forward stochastic differential equation of pricing insurance :

$$
\left\{\begin{array}{cc}
d x(t)=x(t)\left[r_{1} d t+\sigma d w(t)\right] & x(0)=(1-h) P Q \pi(0) \\
d y(t)=\left[r_{0} y(t)+\frac{r}{\sigma} z(t)\right] d t+z(t) d w(t) & y(T)=\xi Q
\end{array}\right.
$$

$z(t)=\sigma y(t) \pi(t)$.On the basic of the gross property $y(t)$ meet the equation (3)we can find the price of insurance $P$, which meets :

$\mathrm{Y}(0)=(1-\mathrm{h}) \mathrm{PQ}$

(2)The deduction of original insurance pricing formula

Theorem 4.1: Suppose the insurance company is risk natural and the backward stochastic differential equation that its property meets is :

$$
\left\{\begin{array}{c}
d y(t)=\left[\mathrm{r}_{0} y(t)+\frac{r}{\delta} z(t)\right] d t+z(t) d w(t) \\
y(\mathrm{~T})=\xi \mathrm{Q} \quad \xi \in(0,1]
\end{array}\right.
$$

$\mathrm{W}(\mathrm{t}), \mathrm{t} \geqslant 0$ is standard Wiener process, $\quad \xi \in_{(0,1] \text { and }}$ $\mathrm{w}(\mathrm{t}), \mathrm{t} \geq 0$ are random variables independently, $r_{0, \mathrm{r}=} r_{1_{-}} r_{0}, \sigma>0$, like mentioned above, the insurance pricing formula of science and technology is :

$$
P=\frac{1}{1-h} E[\xi] \exp \left(-r_{0} T\right)
$$

Prove: first prove

$$
P=\frac{1}{1-h} E[\xi] E[x(T)]
$$

suppose $\mathrm{x}(\mathrm{s})$ is the answer to Ito random equation :

$$
\left\{\begin{array}{c}
d x(s)=x(s)\left[-r_{0} d s-\frac{r}{\sigma} d w(s)\right] \quad s \in[t, T] \\
x(t)=1
\end{array}\right.
$$

From backward stochastic differential equation (4)

we can conclude that

$$
a(t)=-r_{0}, b(t)=-\frac{r}{\sigma}, f(t) 0
$$
so we can know that:

$$
y(t)=E\left[\xi Q x(T) \mid F_{i}\right]
$$

Because:

$$
y(0)=E[\xi Q x(T)]
$$

And because $\xi$ and $\mathrm{w}(\mathrm{t})$ are mutually independent, and $\mathrm{Q}>0$ is a constant, $\mathrm{y}(0)=(1-\mathrm{h}) \mathrm{PQ}$, so the formula (8) can also be written as :

$$
P=\frac{1}{1-h} E[\xi] E[x(T)]
$$

Then prove $E[x(t)]=\exp \left(-\mathrm{r}_{0} \mathrm{~T}\right)$

Suppose $G=\ln x$, then from the Ito differential equation we can conclude that $G$ follows the Wiener process:

$$
d G=\left(-r_{0}-\frac{1}{2}\left(-\frac{r}{\sigma}\right)^{2}\right) d t-\frac{r}{\sigma} d w(t)
$$

Because $r_{0}, \mathrm{r}, \sigma$ are constants, so formula (0) represents $G$ follows a constant drift rate $-r_{0}-\frac{1}{2}\left(-\frac{r}{\sigma}\right)^{2}$ and constant variance rate $\left(-\frac{r}{\sigma}\right)^{2}$,s common Wiener process.

As a result, the change from the present moment $t$ to a future moment $\mathrm{T}$ is of Gaussian distribution, the mean

value is $\left(-r_{0}-\frac{1}{2}\left(-\frac{r}{\sigma}\right)^{2}\right)(\mathrm{T}-\mathrm{t})$, the variance is $\left(-\frac{r}{\sigma}\right)^{2}(T-t)$

So we have: , but change of $G$ in $T-t$ is $\ln x(T)-\ln x(t)$,

$$
\ln x(T)-\ln x(t)\left[N\left(-r-\frac{1}{2}\left(\frac{r}{\sigma}\right)^{2} T,\left(\frac{r}{\sigma}\right)^{2}(T-t)\right]\right.
$$

$N\left(a, b^{2}\right)$ represents a Gaussian distribution, whose the mean is a, standard deviation is $b$.

Suppose $\mathrm{t}=0$, and notice that $\mathrm{x}(\mathrm{t})=1$, so formula (11)changes into :

$$
\begin{aligned}
& \ln x(T) N\left[\left(-r_{0}-\frac{1}{2}\left(\frac{r}{\sigma}\right)^{2}\right) T,\left(\frac{r}{\sigma}\right)^{2} T\right] \\
& \text { Because } E[\ln \mathrm{X}(\mathrm{T})]=-\mathrm{r}_{0}-\frac{1}{2}\left(\frac{r}{\sigma}\right)^{2} T
\end{aligned}
$$

By integral we can get:

$$
E[X(\mathrm{~T})]=\exp \left(a+\frac{b^{2}}{2}\right)
$$

Plug into (12) and we can get :

$$
\left.E[X(\mathrm{~T})]=\exp -r_{0} T\right)
$$

Plug (13) into (9) and we can get (5), the prove ends.

Summary:

With the development of connection of domestic insurance industry and that of international, the urgent problem that our insurance industry faced with is to improve competence. Besides improving the level of management and service quality, it's necessary to decrease the price. It is no doubt that connecting the 
investment of the insurance capital with insurance acceptance, which is the best path to decrease the price. However, this point is just what our insurance industry lacks. Our insurance regulations should set additional interval for price reference. In this way, we can limit some insurance companies set one-sided and high premium rate, and decrease some possibilities of subjective control in pricing premium, and make the price of premium be more fair 、 more objective and more reasonable, and make insurers gain the benefit brought by the development of insurance industry. And we can limit the operating cost of insurance companies objectively. Establishing the database for insurance industry and publicizing guided rate of main kinds of insurance at regular times for insurance companies and insurers to refer to, then we can avoid that price determined only by insurance companies, and make insurance industry enters benign competition and make insurers feel relieved.

\section{ACKNOWLEDGEMENT}

The source of the project: Science and Technology
Financial Key Laboratory of Hebei Province (HBTFKL201405).

\section{REFERENCES}

[1] WU Zhen (School of Mathematics and Systems Science, Shandong University, Jinan 250100, China. Forward-backward stochastic differential equations, linear quadratic stochastic optimal control and nonzero sum differential games[J]. Journal of Systems Science and Complexity. 2005(02)

[2] Chen Jia, Wu Runheng. Theeuropean style of making price for share option in finance mathematics [J].NUCT Journal 2007(01)

[3] Chen Jia, Qiao Jiezeng, Wu Runheng. The development of option pricing theory and backward differential equation[J]. Inner Mongolia Institute of Finance and Economics Journal. 2006(04)

[4] Jiang Songgen, Zhang Dongshan. Empirical analysis on factors affects chinese insurance market. Contemporary Manager. 2006(01)

[5] Du Conghui, Cui Yongwei, Cui Yujie. Empirical analysis on factors affects chinese insurance our insurance industry's development. [J].NUCT Journal 2006(01)

[6] Deng Zhimin, Zhang Runchu. The repricing formula based on investment[J].Applied Mathematics A Journal of Chinese Universities (Chinese version). 2006(01) 